\title{
Working Nature Of Concrete Using Coconut Shell
}

\author{
P.Srikanth Reddy, M.Ramesh Babu, B.Mahesh, Varshanth Kumar
}

\begin{abstract}
In this gift experimental investigation a shot is formed to use low price artifact sort of a coconut shell. within the gift issue the natural mixture is replaced by $100 \%$, $20 \%$, halfhour of coconut shell for various grades of concrete like M20, M25. A comparative study is formed on compressive strength between the standard concrete and coconut shell concrete.
\end{abstract}

Keywords-- cement concrete (CC), Coconut Shell (CS), Cement Mortar (CM), Consistency (P),

\section{GENERAL}

In the recent years, the depletion and rising price of natural aggregates and therefore the amendment within the setting because of the assembly of concrete is raised up extensively.

Many works square measure disbursed on concrete to switch the materials with the wastes shaped by industries and varied sources

\section{Coconut Shell}

Coconut shell are often wont to manufacture light-weight mixture by lowering the density of concrete. In light-weight of this, we must always study concerning the properties of coconut shell in concrete in terms of strength.

\section{Sequence of operation}

The tests square measure conducted on cement to visualize the suitableness of sample in concrete and therefore the investigations were carried on the M20, M25 grade concrete. needed amount of materials is calculated for various grades of concrete and in several percentages of caesium. the desired uniform combine is obtained by mixture of materials. The tests square measure hung on contemporary concrete and hardened concrete.

\section{TESTING PROGRAM}

\section{Fineness of cement}

Fineness or particle size of every cement affects the association rate of any cement and therefore the speed of strength gain. once their square measure smaller particle size

Revised Manuscript Received on April 19, 2019.

P.Srikanth Reddy, Assistant Professor, Department of Civil Engineering, Siddhartha Institute of Technology and Sciences, Hyderabad, Telangana, India.

M.Ramesh Babu, Professor, Department of Civil Engineering, Siddhartha Institute of Technology and Sciences, Hyderabad, Telangana, India

B.Mahesh, Assistant Professor, Department of Civil Engineering, Siddhartha Institute of Technology and Sciences, Hyderabad, Telangana, India.

Varshanth Kumar, Assistant Professor, Department of Civil Engineering, Siddhartha Institute of Technology and Sciences, Hyderabad, Telangana, India. we are going to have bigger space|area|expanse|extent $\}$ to volume quantitative relation then we are able to get the additional area obtainable for water-cement interaction per unit volume. The take a look at is conducted by normal balance IS-90 $\mu$ sieve conformist to IS:460-1965,

\section{Specific gravity of cement}

Specific Gravity explains the comparison between the loads of a volume of a specific material to it of the weight of identical volume of water at a such as temperature. each material has solid particles and pores which can contain water on that. The water-cement quantitative relation content then gets influenced If the cement is exposed to extreme wet. W/C quantitative relation is a crucial issue because it is directly proportional to workability and strength of bonding. take a look at is conducted by relative density bottle. Cement, water and hydrocarbon is employed to work out relative density.

\section{Normal consistency of cement}

The intention of this take a look at is to work out the proportion of water to the load of cement to finish association method or to provide a cement paste of ordinary consistency. Vicats equipment with plunger 10mm DIA is employed during this take a look at. It plays a crucial role in decisive the desired water proportion of initial and final setting time and additionally soundness of cement and additionally compressive strength of cement.

\section{Initial and final setting time of cement}

Initial setting time is that the time once the cement paste starts losing its malleability. it's necessary mixture, transportation, putting and compaction of CC. it's needed to delay the method of association or hardening. And additionally Final setting time is that the time once the cement paste fully looses its malleability. it's the time wherever the concrete gains its strength and original form. It additionally facilitates the removal of system or formwork. $0.85 \% \mathrm{P}$ is that the needed water proportion for this take a look at. in step with IS: 456-2000, the initial setting time mustn't be but thirty min.

\section{Soundness of cement}

Lechatlier methodology confirming to IS 5514-1969 is employed to work out the soundness of cement. it's vital to know that the cement when setting in shall not bear any form of considerable changes in volume. Some cements square measure been determined to bear an oversized 
enlargement when setting and additionally inflicting disruption of the set and hardened mass. Wheir as this may cause a heavy difficulties for the sturdiness of structures if we have a tendency to use this cement. The prime importance in testing of the soundness of cement, to confirm that the cement doesn't show any considerable ulterior enlargement.

\section{Compressive strength of cement}

It is wont to verify the strength of mortar utilized in concrete. It depends on the standard of cement, gradation of sand and quality of water. A cube of volume seven. $06 \mathrm{~cm} 3$ and a moving machine is employed to solid the cubes of $\mathrm{CM}(1: 6)$ and strength take a look at is formed on strength testing machine. As IS code says minimum compressive strength of PPC for seven days is twenty four N/mm2.

\section{Slump cone take a look at}

concrete fluidity/workability is thought by mensuration of Slump. standard for indirect mensuration of concrete consistency or stiffness in a very contemporary state. By this take a look at we have a tendency to come back to grasp concerning the putting conditions of concrete.

\section{Compressive strength of concrete}

A mix proportion is meant as per IS 10262-1982. the subsequent square measure the combo proportions is employed for M20, M25 is 0.55:1:1.6:3.08 and $0.5: 1: 1.2: 2.3$. The specimens of ordinary cubes of $150 \mathrm{~mm} * 150 \mathrm{~mm} * 150 \mathrm{~mm}$ were solid and hold on in situ,free from vibration and at an area temperature for twenty-four hours. take away the mould and immerse the specimen in water. And when twenty eight days casting of the cube specimens were off from the cistern and placed on flat surface for on top of ten minutes to wipe off the surface water and additionally removes the projected fineness on the surface of the specimens. Before putting the specimen in testing machine clean the bearing surfaces of the testing machine and therefore the cube specimen are cleansed. The cube specimen was placed within the machine of $3000 \mathrm{KN}$ capability. Associate in Nursing approximate load of $140 \mathrm{~kg} / \mathrm{sq} . \mathrm{cm} / \mathrm{min}$ till the resistance of the specimen to the increasing load to be sustained, was shown in plate. Compressive strength of the specimen is calculated by dividing the utmost load applied to the specimen throughout the take a look at by mistreatment the cross sectional space of the specimen that average of 3 values of 3 cubes and therefore the individual variation is over 15 August 1945 of the typical was determined. Compressive strength results square measure primarily wont to verify that the concrete mixture as delivered on website meets the necessities of the required strength.

Discussion of take a look at results

\section{CONCLUSIONS}

It was finished that the coconut shells were additional helpful and appropriate as low strength-giving light-weight mixture once wont to replace common coarse mixture in concrete production.

The present project work offers the following:
Results of experiments on compressive strength and workability for various coconut shell replaced concretes are conferred with those of various management concretes. the info show that coconut shell mixture isto sensible to be utilized in place of traditional mixture, because it reduces the density of concrete that falls below light-weight weight concrete.

However, the general strength belittled with coconut shell replacement in comparison to regulate concrete.

Increase in coconut shell replacement leaky voids additionally multiplied.

\section{REFERENCES}

1 K. Gunasekaran, "Utilization of Coconut Shell as Coarse Aggregate in the Development of Lightweight Concrete", PhD Thesis, Department of Civil Engineering, SRM University, Kattankulathur, 2011.

2 Y. Amarnath, and C. Ramachandrudu, "Properties of Concrete with Coconut Shells as Aggregate Replacement", International Journal of Engineering Inventions, Volume 1, Issue 6 (October 2012), pp: 21-31.

3 Concrete technology theory and practice M.S.Shetty.

4 IS456:2000 - Plain and reinforced concrete- Code of practice.

5 IS10262:2009-Guide lines for concrete mix design proportioning. 